\title{
Alleged cnidarian Sphenothallus in the Late Ordovician of Baltica, its mineral composition and microstructure
}

Olev Vinn and Kalle Kirsimäe

Acta Palaeontologica Polonica 60 (4), 2015: 1001-1008 doi:http://dx.doi.org/10.4202/app.00049.2013

Sphenothallus is a problematic fossil with possible cnidarian affinities. Two species of Sphenothallus, $S$. aff. longissimus and S. kukersianus, occur in the normal marine sediments of the Late Ordovician of Estonia. S. longissimus is more common than S. kukersianus and has a range from early Sandbian to middle Katian. Sphenothallus had a wide paleo-biogeographic distribution in the Late Ordovician. The tubes of Sphenothallus are composed of lamellae with a homo-geneous microstructure. The homogeneous microstructure could represent a diagenetic fabric, based on the similarity to diagenetic structures in Torellella (Cnidaria?, Hyolithelminthes). Tubes of Sphenothallus have an apatitic composition, but one tube contains lamellae of diagenetic calcite within the apatitic structure. Sphenothallus presumably had origi-nally biomineralized apatitic tubes. Different lattice parameters of the apatite indicate that biomineralization systems of phosphatic cnidarians Sphenothallus and Conularia sp. may have been different.

Key words: Cnidaria?, Sphenothallus, apatite, microstructure, Ordovician, Sandbian, Katian, Estonia.

Olev Vinn [olev.vinn@ut.ee] and Kalle Kirsimäe [kalle.kirsimae@ut.ee], Department of Geology, University of Tartu, Ravila 14A, 50411 Tartu, Estonia.

This is an open-access article distributed under the terms of the Creative Commons Attribution License (for details please see creativecommons.org), which permits unrestricted use, distribution, and reproduction in any medium, provided the original author and source are credited. 
